\title{
Pictures, Titles, Depictive Content
}

Kendall L. Walton, Ann Arbor

\section{Pictures and Depictive Gontent}

I understand pictures to be objects whose function, in a given social context, is to serve as props in visual games of make-believe. ${ }^{1}$ Some prefer to understand them, what it is to be a picture, in other ways. I shall not defend my account here, not directly, nor shall I argue against alternatives. But it does seem to me to be nearly undeniable that viewers of pictures do, often if not always, engage in visual games of make-believe of approximately the kind I have proposed, and that their service as props in such games is a hugely important part of what makes pictures interesting and valuable. This engagement needs to be recognized no matter how one chooses to define 'picture' (or 'pictorial representation', or 'depiction'). In the present essay I examine the visual games themselves, the various ways in which viewers participate in them in various kinds of cases, the circumstances that encourage or demand certain participative activites, and how these are related to a picture's depictive content. I shall be especially interested in how titles sometimes affect appreciators' visual games, and the depictive content of pictures.

A visitor to the National Gallery in London, viewing Rubens' landscape, might describe her experience in words like these:

Looking out on a vast landscape, I see a hunter and his dog in the shadows near me, as a farm wagon passes by, then catch sight of a small footbridge crossing a stream, and beyond that a group of grazing cattle. I look to see what the hunter's 


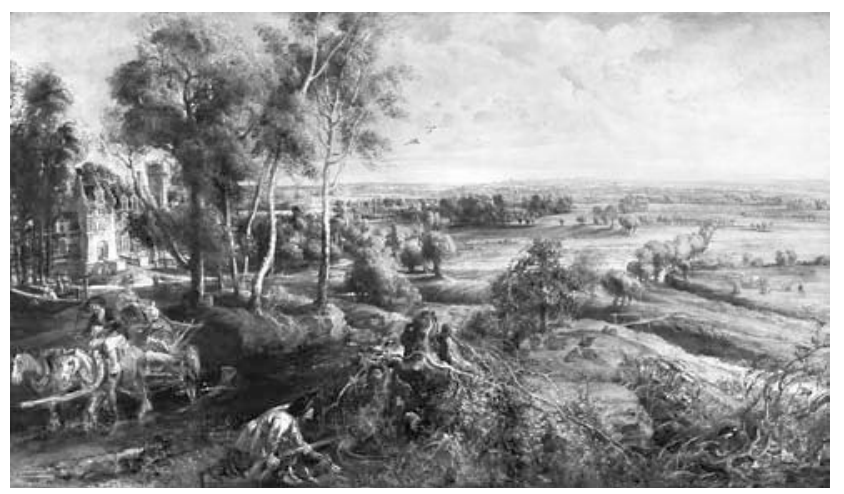

Fig. 1

\section{An Autumn}

Landscape with a View of Het Steen in the Early Morning

Peter Paul Rubens ( 1636)

quarry might be, and notice several birds in the field. Examining them more carefully I identify them as partridges. I pick out a blackberry bush in the foreground. Watching the clouds drifting lazily across the sky, I spot a couple of birds circling in the air. Finally I catch sight of a village on the horizon, the town of Malines.

These are words that one could use (literally) in describing an experience of an actual scene. The viewer in front of the picture - let's call her Robin - is not speaking literally. She is reporting her imaginative experience, what she imagines seeing, noticing, looking for, watching, recognizing, etc. as she scans the canvas. She is describing an elaborate engagement in a visual game of make-believe, in which the picture serves as a prop.

Participation in visual games of make-believe using pictures as props is a complex perceptual and imaginative activity. It involves imagining performing visual actions, sometimes actions of many kinds, as in Robin's case, but often fewer and simpler ones. At a minimum, one imagines seeing the depicted objects or objects of the kinds that are depicted, as one scans the picture surface. One also imagines one's actual visual experience of the picture to be a visual experience of these objects or objects of these kinds. The viewer of Rubens' Autumn Landscape

(a) sees the picture, the pattern of colored marks on the picture surface.

(b) imagines seeing trees and fields, a horse cart and a hunter, clouds in the background, buildings on the left, etc. ${ }^{2}$

(c) imagines her actual perceiving of the picture surface to be a perceiving of trees and fields, clouds, a horse cart, etc. 
When (a), (b), and (c) are true let's say that the viewer sees ${ }^{\mathrm{I}}$ trees and fields, etc. (I claim that this complex experience constitutes, approximately, what Wollheim and others call seeing trees, fields, etc. in the picture.)

Much remains to be said about how the imaginings and the perceivings are related. Michael Podro thinks that on my account of depiction, 'having our attention drawn to the material characteristics of the painting disrupts our imaginative seeing. ${ }^{3}$ It is true that such disruption can occur; one can be so focused on properties of the paint (especially properties that lack depictive significance) that one's imaginative seeing of trees and fields, or whatever, is curtailed. But my view is not that this always or generally happens. The imaginings are in part about one's perception of features of the canvas; we imagine it to be the perceiving of trees and fields. And these perceptions guide and sustain our imaginings, in ways that Podro has explored. ${ }^{4}$

We do not always notice the features that we perceive. A splotch of paint of one shade of red may depict a house roof as having a different shade. Viewers may imagine seeing the roof's shade, but fail to notice the different shade of the splotch, fail to notice that it is different. Nevertheless, it is because one sees the shade of the splotch, because one is at least implicitly aware of it, that one is induced to imagine the color of the roof. If attending to the shade of the splotch interferes with the imagining, this is only contingently so. Certainly we can be fully aware that the splotch is red (even if we aren't aware of its shade of red), while imagining seeing the redness of the roof.

Pictures, I said, are objects whose function is to serve as props in visual games of make-believe. This is a normative notion. It is understood in a given social context that a picture is to be used as a prop in visual games of makebelieve of a certain kind, that this is a proper or appropriate use of it. The frost on the window photographed in figure 2 (overleaf) might serve as a prop in a visual game of make-believe. Observing it, one might imagine seeing a jumble of vegetation (or something else), and imagine one's visual experience of the frost to be a visual experience of vegetation; one might see $e^{\mathrm{I}}$ vegetation. But it is not the function of the frosted window to be so used; that isn't how it is supposed to be used. So it does not count as a picture in my sense. (It might be given this function in a certain social context, however, thereby becoming a picture relative to that context. The photograph is a picture, of course, a picture of frost on a window.)

Rubens' landscape qualifies as a picture because its function is to serve as a prop in visual games of make-believe of certain sorts. What makes it a picture 


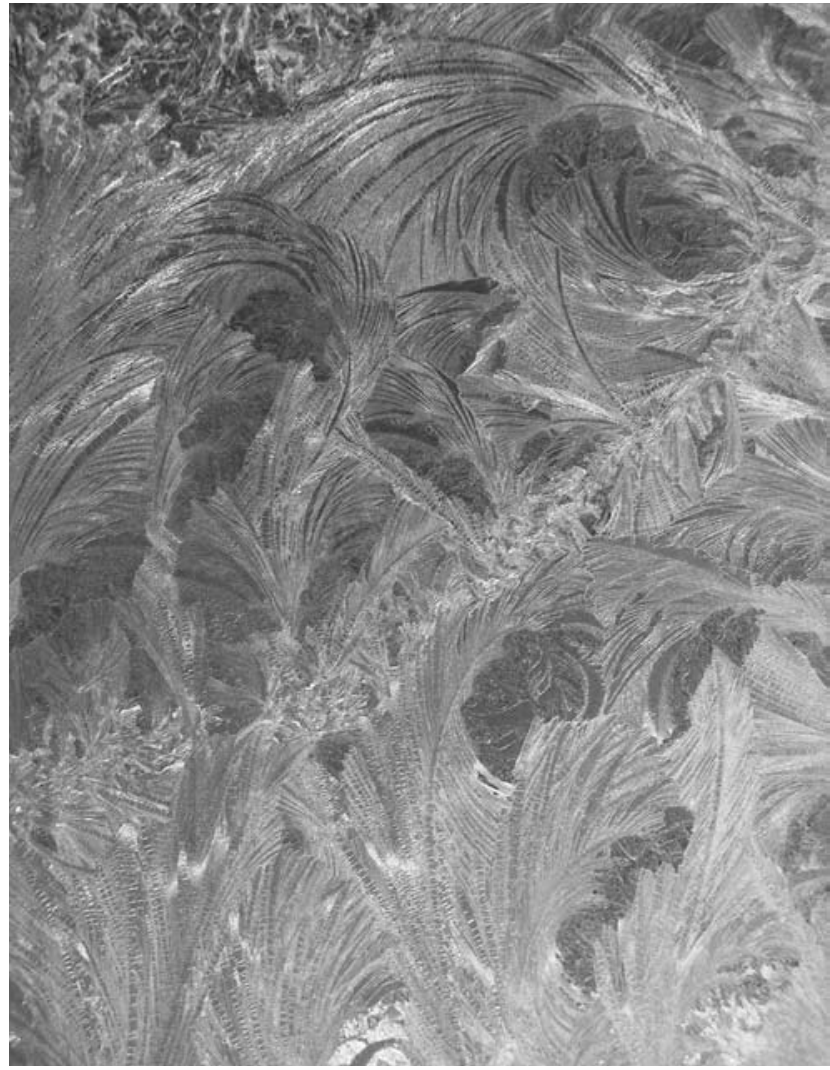

Fig. 2

Frost on Window

Photograph by

Kendall Walton

of trees, fields, etc.? What gives it its depictive content? Approximately this: the visual games in question are ones in which viewers are to $s e e^{\mathrm{I}}$ trees and fields. In general, to be a picture of a $\phi$ is to have the function of serving as a prop in visual games in which participants are to $s e e^{\mathrm{I}}$ a $\phi$ - they are to see the picture, imagine seeing a $\phi$ and imagine their perceiving of (part of) the picture to be a perceiving of a $\phi$. This is too simple as it stands; it needs clarification and probably emendation. But it will do for now.

The depictive contents of pictures are thus linked to imagined actions of seeing the things that are depicted. But appreciators' participation in their visual games often include many more imagined visual actions or experiences than this. Robin looks to see what the hunter's quarry is, examines the birds 
carefully, and identifies them as partridges - she imagines doing these things and imagines of actual visual actions she performs vis à vis the picture that they are actions of examining the birds carefully, etc. We can put this by saying that she looks to see ${ }^{\mathrm{I}}$ what the hunter's quarry is, examines ${ }^{\mathrm{I}}$ the birds carefully, identifies ${ }^{\mathrm{I}}$ them as partridges, etc. Different appreciators will engage in the make-believe differently, performing (in imagination) different visual actions. One viewer of Rubens' landscape might stare intently ${ }^{\mathrm{I}}$ at the couple on the bridge, while another merely glances casually ${ }^{\mathrm{I}}$ at them. One might examine $^{\mathrm{I}}$ the architectural details of the castle on the left before attending to the farm animals on the right, another afterwards. A viewer might, or might not, look for ${ }^{\mathrm{I}}$ signs of deer or a snake in the grass, or count ${ }^{\mathrm{I}}$ the cattle in the pasture. Viewers can to a considerable extent choose how to look at the picture, which actions to perform in imagination. One can decide how long to look $k^{\mathrm{I}}$ at the castle, and whether to look for ${ }^{\mathrm{I}}$ a snake in the grass. Many of these actions are more or less optional, in the sense that one need not perform them in order fully and properly to understand and appreciate the painting. The painting's function is to serve as a prop in games that allow for these various imaginative/perceptual activities, but do not demand all of them. Seeing ${ }^{\mathrm{I}}$ trees and fields is not exactly optional, however. Viewers must do this, normally, in order to identify the picture's depictive content, to discover that it is a picture of trees and fields. ${ }^{5}$

Fig. 3

The Fall of Icarus

Pieter Bruegel

$(\sim 1558)$

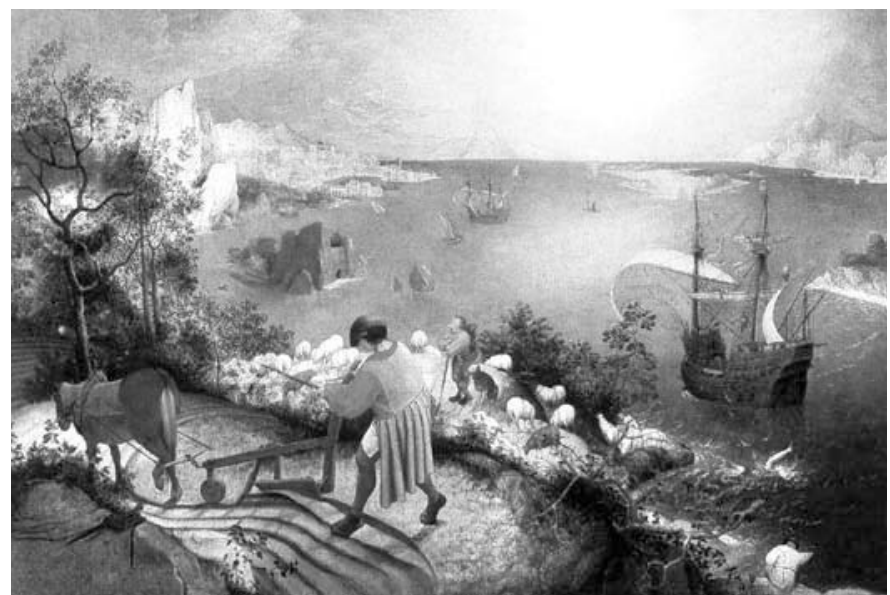


Not all representing by pictures is depicting. Representation (in the sense that interests me now) is a matter of what is true in the world of the picture. It will do, for now, to say that a giraffe exists in the world of a picture (that it is fictional in the work world that a giraffe exists), and that the picture represents a giraffe, just in case appreciators are to imagine a giraffe. There is no requirement that they imagine seeing a giraffe, or that they $s e e^{\mathrm{I}}$ a giraffe. ${ }^{6}$

Pieter Bruegel's Fall of Icarus represents Icarus plummeting into the ocean. It depicts him floundering in the water, but it doesn't depict his falling. Viewers are expected to $s e e^{\mathrm{I}}$ him flounder, but not to $s e e^{\mathrm{I}}$ him fall. The painting also represents Icarus' entire body, but depicts only his legs protruding from the water. It is fictional, true in the picture world, that he has a complete torso and head, though viewers do not imagine seeing them, do not see $e^{\mathrm{I}}$ them.

\section{Titles}

The depictive content of a picture depends largely on the pattern of marks on the picture surface. It is because they are as they are that the picture depicts a giraffe, or a farm wagon, or whatever. Typically, we are able to tell what a picture depicts just by looking at the marks. Observing them, we find ourselves imagining seeing a giraffe and imagining our seeing of the marks to be a seeing of a giraffe - the marks induce us more or less automatically to $s e e^{\mathrm{I}}$ a giraffe. We ordinarily accept that a picture's function is to elicit the perceptual/imaginative experience it naturally induces. So we take the picture to depict a giraffe.

The marks on picture surfaces do not act alone, however. General background information of various kinds, much of it internalized, is inevitably involved. I am interested now in contextual circumstances specific to particular works, however, circumstances that play a role in eliciting viewers' imaginings and establishing what pictures depict - sometimes whether they depict at all. There are several importantly different kinds of such circumstances. Prominent among them are titles and other texts associated with pictures. ${ }^{7}$

Paul Klee provides a rich array of examples. The Singer of the Comic Opera depicts a comic opera singer. That it depicts a woman is obvious from the marked surface alone. The title makes it a picture of a comic opera singer. Given the title, we are to imagine seeing a comic opera singer and to imagine 
Fig. 4

The Singer of the Comic Opera

Paul Klee (1925)

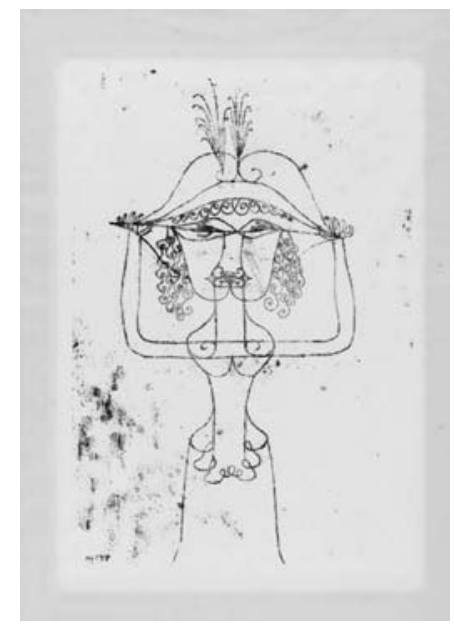

our perception of the picture surface to be a perceiving of a comic opera singer. We don't imagine our perception of the title to be a perceiving of a comic opera singer (or anything else). It is the marks, not the title, that do the depicting. But what they depict, what we imagine our seeing of them to be seeing of, is determined partly by the title.

But for their titles, figures 5 and 6 (overleaf) might reasonably be understood to be mere designs, geometric patterns lacking depictive content. Given the titles, however, one depicts waves, the other a castle and the sun. The Sydney Opera House suggests sails. If it were titled, 'Sailing to Singapore' it would depict them; seeing ${ }^{\mathrm{I}}$ sails would then be called for.

Music is often depictive, but rarely without the assistance of a title or text - the lyrics of a song, for instance. With textual help, music can depict gurgling brooks, galloping horses, sighs and laughter, and much else. (These are auditory depictions: listeners imagine hearing a gurgling brook, and imagine of their hearing of the music that it is an auditory perception of a brook.) Kodaly's Hary Janos Suite begins with an orchestral sneeze. Without a hint from the program notes, one might fail to recognize it. With the hint, the sneeze is unmistakable, remarkably realistic.

A couple of questions: First, is it really the title that does the job in these cases, helping to determine what is depicted, or is it rather the artist's intention, of which the title is an indication? Is it because of the title or the 


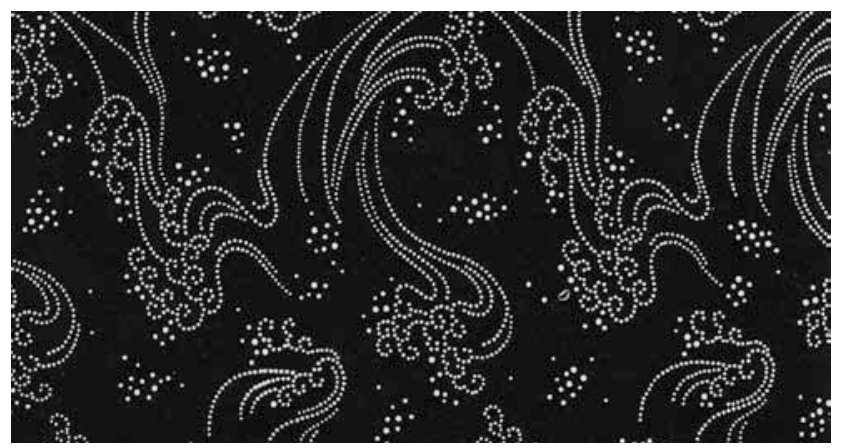

Fig. 5

Waves (Nami)

Japanese,

Edo period

(1603-1868)

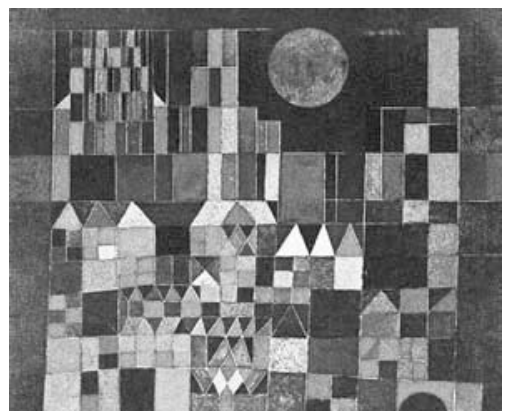

Fig. 6

\section{Castle and Sun}

Paul Klee (1928)

intention that one is to $s e e^{\mathrm{I}}$ a comic opera singer, or waves, or a castle and the sun? It could be either. Which it is might vary depending on the social context. But since titles and intentions coincide in most instances, almost certainly including the above examples, the best answer may be that usually there just is no fact of the matter as to whether a title or an intention contributes to a picture's depictive content. I adopt the working assumption that it is the titles that matter in the cases I shall be discussing. If the titles don't play the roles I attribute to them, then intentions, or more likely advertised intentions, do.

A more interesting question is this: Is it depiction that these titles contribute to, or just representation?

Eduard Hanslick raised a similar issue concerning music. In arguing against the idea that music can express or represent emotions or feelings, he claimed that 'an operatic melody ... which had very effectively expressed anger ... might just as effectively render words expressing the exact opposite, namely, 
passionate love. ${ }^{8}$ He cites several particular cases in which, he contends, the same music has been appropriately attached to texts describing vastly different emotions. The conclusion is supposedly that it is the text, not the music, that does the representing or expressing. ${ }^{9}$

This conclusion is unwarranted. What feeling or emotion a passage of music expresses may depend partly on a text, yet it is the music that does the expressing. We will hear the same melody or musical passage differently under the influence of different associated texts, in one case hearing anger in it, in another passionate love. Substituting one text for another can transform spasms of fury into pangs of love. Nevertheless, it is in the music that we hear these emotions. (I remain neutral here about just what musical expression of emotions consists in, assuming only that it is largely a matter of hearing the music in a certain way.)

Only the title of The Singer of the Comic Opera introduces the notion of a comic opera singer; the image itself doesn't. And the image could have had a different title, e. g. Dressed for Church, or Painted Doll. Is it only the title, then, that represents a comic opera singer? The title doesn't do any depicting. So must we say that the picture-title complex doesn't depict but merely represents a comic opera singer?

This example is unlike Bruegel's Icarus. Viewers do not see $e^{\mathrm{I}}$ Icarus falling. The picture does not depict the fall, but merely represents it. Viewers of Klee's picture, noticing the title, do $s e e^{\mathrm{I}}$ a comic opera singer (and it is the function of the picture to elicit this perceptual/imaginative experience). So, on the rough account of depiction given above, the picture assisted by its title depicts a comic opera singer. The title is likely to affect viewers' visual/ imaginative experiences of the picture in other ways as well. Realizing that the woman is a comic opera singer, one will probably look at her differently (in imagination) — noticing ${ }^{\mathrm{I}}$, paying attention ${ }^{\mathrm{I}}{ }^{\mathrm{I}}$ her theatrical demeanor or dramatic gestures, for instance, or perhaps looking for ${ }^{\mathrm{I}}$ signs of theatricality and not finding ${ }^{\mathrm{I}}$ them. Real life visual experiences are influenced greatly by background knowledge, by what we know independently, or believe or suspect, about the objects around us. It is not surprising that titles should influence our imaginative/perceptual experiences of pictures also, often in analogous ways.

The Singer of the Comic Opera depicts a woman. It also depicts a comic opera singer. But to note only this is to neglect an important difference, one naturally expressed by saying that the drawing depicts a woman as a woman, but does not depict her as a singer of comic operas. 
One might suppose that titles can influence what pictures depict, but not what they depict things as, the latter being up to the images alone. This would be a mistake. Figure 5 (Nami) depicts waves as waves. Yet it does so only with the help of the title. One difference between it and The Singer of the Comic Opera is that viewers of Nami imagine recognizing the waves as such. Viewers of Klee's drawing probably do not imagine recognizing the woman as a comic opera singer - in any case they are not expected to; they imagine seeing what they know to be a comic opera singer. More precisely, the former recognize $\mathrm{I}^{\mathrm{I}}$ the waves as waves, $s e e^{\mathrm{I}}$ that they are waves, whereas the latter $s e e^{\mathrm{I}}$ (what they know to be) a comic opera singer, but recognize ${ }^{\mathrm{I}}$ her only as a woman. I am not sure how best to define 'depiction as'. Probably a sufficient (but not necessary) condition for depicting something as a $\phi$ is possessing the function of serving in visual games of make-believe in which one is to recognize ${ }^{\mathrm{I}}$ something as a $\phi$, i. e. (approximately) to $s e e^{\mathrm{I}}$ it and see that $\mathrm{I}^{\mathrm{I}}$ it is a $\phi$. Nami satisfies this condition for depicting waves as waves. The Singer of the Comic Opera does not satisfy it for depicting a comic opera singer as such.

\section{Consequences}

So titles often have significant bearing on the depictive content of pictures, not just their representational content. (Not all titles serve this function, of course.) Some will want to understand 'depiction' (and 'depiction as') more narrowly than I do, excluding the operation of titles, so that a person familiar with a given depictive system and possessing relevant general background information can ascertain a picture's depictive content just by examining the image. We needn't quarrel about how to define these words. But we must have resources to characterize the ways in which titles can affect our understanding and experience of pictures. We need to be able to account for the similarities and differences among the several examples that I have examined, and others like them.

The role of titles in depiction (as I am understanding it) has ramifications for several common assumptions about pictures. According to Robert Hopkins, 'Only what can be seen can be depicted, and everything is depicted as having a certain (visual) appearance. I can't depict an electron (though I can use a picture of something else to represent one nondepictively). ${ }^{10}$

Consider a picture of a refrigerator magnet surrounded by dots, and 
titled Magnet and Electrons. Arguably viewers are to imagine seeing electrons; and are to $s e e^{\mathrm{I}}$ electrons. This is depiction of a very minimal kind, at best. ${ }^{11}$ But this picture does need to be distinguished from one that merely represents electrons in the way that The Fall of Icarus represents Icarus' downward motion, as well as from linguistic descriptions of or references to electrons. Does the picture depict electrons 'as having a certain visual appearance'? Perhaps it depicts them as looking like dots, though this is not an appearance electrons actually have. It is also not an appearance distinctive enough to enable one to recognize electrons as such, even if it were theirs. A different picture might have tiny elephant shaped marks (perhaps ones of different sizes and shapes) in place of the dots. This might be an instance of using 'a picture of something else to represent [electrons] nondepictively' ('nondepictively' at least in the sense that it doesn't depict electrons as elephantlike). But there could be a myth, a fiction, that electrons do look like little elephants; the picture might even be the source of this fiction. Then viewers may be expected to imagine - to imagine - recognizing electrons as such by their elephant-like appearance, even though they can't recognize electrons in real life, least of all by an appearance of that kind. On one understanding, this picture depicts electrons as electrons. ${ }^{12}$ Of course this kind of case needs to be distinguished from ones in which viewers imagine recognizing things by appearances they exhibit in real life.

Regarding pictures as props in visual games of make-believe makes the enormous vocabulary with which we describe (real life) visual experiences and activities available for understanding pictures of many different kinds, and many different kinds of experiences viewers have of them. We have seen how thinking of pictures in this way helps us understand much of this variety, some of it resulting from the role of titles in guiding and directing viewers' participation. I doubt that there is any other natural or perspicuous way of accounting for it. 


\section{Notes}

1 The following brief sketch of my account of depictive representation and visual games of make-believe, using Rubens' landscape as an illustration, is largely borrowed from my 'Experiencing Still Photographs: What Do You See and How Long Do You See It?', in: Walton, Marvelous Images: On Values and the Arts. (New York: Oxford University Press, 2008), 164-166. I explain and defend this account more thoroughly in Mimesis as Make-Believe (Cambridge: Harvard University Press, 1990) and in other essays in Marvelous Images.

2 Imagining seeing is not reducible to imagining that one sees. Cf. Mimesis as Make-Believe, p. 29.

3 Michael Podro, Depiction (New Haven, Yale University Press, 1998), p. 28. Thanks to Wolfram Pichler.

4 An especially interesting suggestion that Podro makes about links between the seeing and the imagining, is that a line of a drawing may 'relate itself to the figure twice over, once by its shape and once by its apparent impulse.' (Depiction, p. 9). One way in which the impulse may relate to the depicted figure is illustrated, I believe, in a Van Gogh self portrait that I discussed elsewhere. Nervous lines in the background tend to make viewers nervous, and encourage them to think of themselves as infected by the pictured van Gogh's nervousness. See my 'Projectivism, Empathy, and Musical Tension.' Philosophical Topics (1999) 26, § 10 .

5 When a viewer sees ${ }^{\mathrm{I}}$ a castle, or looks for ${ }^{\mathrm{I}}$ a snake, for instance, it will be true-in-theworld-of-her-game, i.e. (in my terminology) fictional in her game-world, that she sees a castle, or looks for a snake. (Her game world is distinct from the world of the picture, the work world). These propositions could be fictional in her game-world even when she does not $s e e^{\mathrm{I}}$ a castle, or look for $r^{\mathrm{I}}$ a snake, but only in instances of an unusual kind that need not concern us here.

6 Several qualifications and clarifications are needed here.

7 Photographed objects play a similar role. Photographs are not necessarily pictures of what they are photographs of. A still from The Wizard of $\mathrm{Oz}$ depicts fictional Dorothy, though it is a photograph of the real Judy Garland, not of Dorothy. But many photographs are understood to depict whatever they are photographs of, even if this depictive content is not evident from the image itself. In The Wizard of $O z$ case, the story line of the movie trumps the photographed object in determining what the picture depicts.

8 Eduard Hanslick, On the Musically Beautiful: A Contribution Towards the Revision 
of the Aesthetics of Music, translated by Geoffrey Payzant (Indianapolis: Hackett, 1986), p. 17.

9 Hanslick does not seem to recognize a distinction much like those recent theorists draw between representing and expressing, nor any like mine between depicting (auditorily) and representing.

10 Hopkins, 'The Speaking Image', in: Matthew Kierean, Contemporary Debates in Aesthetics and the Philosophy of Art (Oxford: Blackewells, 2006), p. 146. See also Dominick Lopes, 'The Domain of Depiction', in: Matthew Kierean, Contemporary Debates in Aesthetics and the Philosophy of Art (Oxford: Blackewells, 2006). I pass on the question of whether it really is impossible to see electrons.

11 To be a picture something must have the function of serving in relatively rich visual games of make-believe. (Cf. Mimesis as Make-Believe, p. 296.) The visual game involving electrons, in this example, is hardly a rich one, but let us assume that the game involving the magnet is rich enough for the marked surface to count as a picture of a magnet.

12 There are myths about how Socrates and Jesus looked, fostered largely by pictures with appropriate titles. Probably viewers of these pictures recognize $e^{\mathrm{I}}$ Socrates or Jesus, though not by appearances by means of which they could actually recognize them, and it seems not unreasonable to describe the pictures as depicting Socrates as Socrates, and Jesus as Jesus. A single picture of a person with distinctive features, titled 'Socrates' might be understood to introduce a fiction that Socrates looked like that, and count as depicting him as Socrates. 
